\title{
Modeling the Impact of Innovation on Economic Quality and Environmental Pollution Change under Consideration of Environmental Regulation
}

\author{
Xinfei Li, ${ }^{1}$ Yuan Tian, ${ }^{2}$ Yueming Li, ${ }^{1}$ Chang $\mathrm{Xu},{ }^{3}$ Xiaobing Liu, ${ }^{4}$ and Baodong Cheng $\mathbb{D}^{1}$ \\ ${ }^{1}$ School of Economics and Management, Beijing Forestry University, Beijing 100083, China \\ ${ }^{2}$ Business College, Beijing Union University, Beijing 100025, China \\ ${ }^{3}$ School of Finance and Public Management, Anhui University of Finance and Economics, Bengbu 233030, China \\ ${ }^{4}$ School of Economics and Management, Beijing University of Agriculture, Beijing 102206, China
}

Correspondence should be addressed to Baodong Cheng; baodong@bjfu.edu.cn

Received 10 June 2021; Revised 4 July 2021; Accepted 9 July 2021; Published 16 July 2021

Academic Editor: Daqing Gong

Copyright $\odot 2021$ Xinfei Li et al. This is an open access article distributed under the Creative Commons Attribution License, which permits unrestricted use, distribution, and reproduction in any medium, provided the original work is properly cited.

\begin{abstract}
Under the constraints of resources and the environment, exploring the channels to improve the quality of China's economy is very important for China's current sustainable development. Therefore, this paper studies whether innovation can improve the quality of China's economy and explore the path of sustainable development from the perspective of the city. Based on the Malmquist-Luenberger index and DEA-Malmquist index, this paper, respectively, measures the green total factor productivity (GTFP) and total factor productivity (TFP) of 193 cities in China. On the basis of obtaining the GTFP, TFP, and various pollutant emissions of 193 cities, this paper selects environmental regulations as the threshold variable and the number of urban patents as the explanatory variable to measure the level of urban innovation. On this basis, we examine the impact of innovation quality on economic quality and environmental pollution under different environmental regulatory intensities. The research results show that the impact of innovation on GTFP and TFP under different environmental regulations is always positive, but the impact coefficient and significance level vary. In addition, the impact of innovation on $\mathrm{SO}_{2}$ emissions under different environmental regulations has also changed. With the increase of environmental regulations, the effect of reducing emissions is gradually significant. The conclusion of this paper better interprets the development of TFP and GTFP under the innovation-driven strategy, provides a decision-making basis for departments at all levels to formulate innovation support policies, and explores the path of sustainable development.
\end{abstract}

\section{Introduction}

With the rapid development of China's economy, environmental problems have begun to become prominent [1]. In order to improve the environmental problems, the Chinese government has made a lot of efforts, mainly in the following two aspects. On the one hand, in order to deal with negative externalities, the government has strengthened the implementation of environmental regulatory policies. On the other hand, in order to seek the coordinated development of the economy and resources and environment, the government's requirements for enterprise technological innovation are constantly increasing.
Under the constraints of resources and the environment, exploring the channels to improve the quality of China's economy is very important for China's current sustainable development. However, traditional total factor productivity (TFP) does not consider environmental pollution and cannot accurately measure the level of China's economic quality. In this situation, green total factor productivity (GTFP) has become the main driving force and quantitative standard for driving China's economic development [2]. In practice, scholars have conducted a series of discussions on the improvement paths of GTFP, focusing on government systems [3], technological development [4], foreign trade [5], and financial development [6]. Among them, the role of 
environmental regulation in the improvement of GTFP has aroused heated discussion in academic circles. Existing research shows that the "compliance cost effect" [7] and the "innovation compensation effect" [8] exerted by environmental regulations would directly affect the investment of urban enterprises in innovation. Furthermore, technological innovation results would have an impact on GTFP. In this context, exploring the impact of environmental regulations and innovation quality on the improvement of GTFP has become an inevitable trend of current social sustainable development. Some scholars believe that strict environmental regulations can increase production costs and have adverse effects on productivity, which is the "pollution refuge hypothesis" [9]. However, more scholars believe that strict environmental regulations would prompt domestic industries to take the lead in developing innovative technologies that are more compatible with the environment $[10,11]$ to improve GTFP, which is the "Porter Hypothesis" [12-14]. Therefore, environmental regulation can affect the mechanism of innovation on GTFP. In this context, exploring the impact of environmental regulation and innovation quality on GTFP has become an inevitable trend of current social sustainable development.

As technological innovation plays an important role in the increase of productivity under environmental regulation, some scholars have made some useful explorations. However, there are still few documents in this area, and there are certain research flaws. (1) The literature focuses more on the research on the impact of innovation on TFP and seldom focuses on GTFP, and there is no comparison of the impact of innovation on the two types of productivity. (2) Whether the intensity of environmental regulation has a negative impact on innovation cannot be determined, and this directly affects the impact of innovation on GTFP. The existing literature does not carry out research on the innovation of GTFP under different environmental regulatory intensities. (3) Does innovation under different environmental regulatory intensities have a direct effect on energy conservation and emission reduction, and is this effect different from GTFP? Existing research rarely pays attention to this. Therefore, based on the GTFP, TFP, and pollutant emissions of 193 cities, this paper selects environmental regulation as the threshold variable and the number of urban patents as the core explanatory variable and analyzes the impact of innovation quality on economic quality and environmental pollution under different environmental regulation intensities.

The innovations of this article are as follows. (1) On the basis of previous research, this study takes innovation and productivity as the research object to reveal the relationship between the two and can better interpret the development of TFP and GTFP under the innovation-driven strategy. (2) This study takes into account the possible nonlinear relationship between innovation quality and productivity, draws on previous research methods to make environmental regulations as a threshold variable, and uses a panel threshold model to investigate the relationship between innovation quality and productivity under different environmental regulatory levels. (3) The main difference between
TFP and GTFP is whether to consider pollutant emissions. Therefore, in addition to GTFP and TFP, the explained variables also include pollutant emission indicators to more intuitively analyze the impact of innovation and improvement on economic quality and environmental pollution under different environmental regulations.

\section{Theoretical Basis}

Innovation has always been one of the important factors affecting the increase of GTFP $[15,16]$. For example, Huergo and Jaumandreu [17] believed that the innovation would lead to the $1.5 \%$ increase in TFP of Spanish manufacturing companies based on the data of 2,300 Spanish companies from 1990 to 1998. Duguet [18] found that radical innovation by companies led to the $2.2 \%$ increase in TFP taking French manufacturing companies from 1986 to 1990 as a sample. Although scholars have achieved fruitful results about the impact of innovation on TFP, previous studies have not incorporated factors such as environmental pollution into the TFP measurement framework. Therefore, incorporating environmental factors into the TFP measurement framework to obtain GTFP is a progress in evaluating the development economy. In terms of GTFP calculations, beginners started calculations by substituting pollution emissions into the extended C-D production function. After that, academia improved the calculation methods of GTFP. Fare et al. [19] regarded environmental pollution as an undesired output and constructed a directional distance function. However, this method is based on the fact that the input or output is unchanged, and the other is changed to calculate the input-output efficiency. The calculation model, therefore, has angular and radial defects. Aiming at the shortcomings of the directional distance function to measure GTFP, Fukuyama and Weber [20] used the Luenberger productivity index to calculate GTFP. Regarding the empirical aspects of GTFP, most scholars believed that innovation would be conducive to the improvement of GTFP under environmental regulations [21].

Environmental regulation can further affect GTFP by changing the level of innovation. The first one is based on the "following cost effect." Environmental regulation inhibits innovation and has a negative impact on GTFP. In regions or countries with high intensity of environmental regulation, producers have to introduce new environmental protection technology to produce products that meet the requirements of environmental regulation, so there is not enough money to invest in patent research and development, which inhibits the output of innovation, and makes the GTFP unable to improve in the long run [22, 23]. For example, Wagner [24] used the data of the German manufacturing industry to find that the number of German manufacturing patents was inversely proportional to the intensity of environmental regulation, and there was a significant negative correlation between them. Preston and Jrgen et al. [25], based on the short-term carbon pricing policy implemented in Australia, found that environmental regulation could inhibit innovation. The second is the "compensation effect of 
innovation." Strict environmental regulation would not inhibit innovation. On the contrary, it could promote innovation to a certain extent and help enterprises improve GTFP. For example, Hamamoto [26] found that with the increase of R\&D (Research and Development) investment, technological innovation capacity would also be enhanced. Yang [27] found that environmental regulation could promote innovation through empirical research on Taiwan's manufacturing data. This would have a positive impact on the improvement of GTFP.

The general TFP does not take into account the loss of environmental resources caused by economic growth, which distorts the evaluation of social welfare changes and economic performance. GTFP adds variables reflecting environmental changes in TFP calculation, which makes up for this. Therefore, this paper selects GTFP and TFP as the index of economic quality and analyzes the impact of innovation on economic development. Based on the results of 193 cities, the paper chooses environmental regulation as a threshold variable and the number of urban patents as the core explanatory variable to measure the level of urban innovation. On this basis, this paper analyzes the impact of innovation quality on GTFP and TFP under different environmental regulation intensities. The difference between TFP and GTFP is whether pollutant emission is considered. Therefore, in addition to GTFP and traditional TFP, the explained variables also add pollutant emission indicators to analyze the impact of innovation and improvement on environmental pollution under different environmental regulations. The framework of this paper is shown in Figure 1.

\section{Methodology}

\subsection{Research Data}

3.1.1. Measurement of Total Factor Productivity. At present, the measurement methods of TFP mainly include the production function method, DEA-Malmquist index method, and SF stochastic frontier method. Compared with other methods, the DEA-Malmquist index is widely used by scholars due to its nonparameterization and the fact that it does not consider variable price information and the elasticity coefficient of each input element. Based on research needs, this article will also use the DEA-Malmquist index method to measure the city's total factor productivity [28].

$$
\begin{aligned}
M_{t}^{t+1} & =\left[\frac{D_{i}^{t}\left(x^{t+1}, y^{t+1}\right)}{D_{i}^{t}\left(x^{t}, y^{t}\right)} \times \frac{D_{i}^{t+1}\left(x^{t+1}, y^{t+1}\right)}{D_{i}^{t+1}\left(x^{t}, y^{t}\right)}\right]^{1 / 2} \\
& =\frac{D_{i}^{t+1}\left(x^{t+1}, y^{t+1}\right)}{D_{i}^{t}\left(x^{t}, y^{t}\right)}\left[\frac{D_{i}^{t}\left(x^{t+1}, y^{t+1}\right)}{D_{i}^{t+1}\left(x^{t+1}, y^{t+1}\right)} \times \frac{D_{i}^{t}\left(x^{t}, y^{t}\right)}{D_{i}^{t+1}\left(x^{t}, y^{t}\right)}\right]^{1 / 2}=\mathrm{EC}_{t}^{t+1} \times \mathrm{TC}_{t}^{t+1} .
\end{aligned}
$$

Among them, $x$ and $y$, respectively, represent the input and output vectors. $D$ represents the production distance function. The DEA-Malmquist index can be further decomposed into technical progress index (TC) and technical efficiency index (EC).

The DEA-Malmquist index is the TFP growth rate, which is a dynamic indicator that reflects the chain improvement. We need to convert the DEA-Malmquist index to TFP. That is, we set 2005 as the base period. Specifically, the TFP in 2005 is 1, and the TFP from 2006 to 2016 is obtained in turn. Therefore, this paper selects 2006-2016 TFP data for the following threshold empirical research.

3.1.2. Measurement of Green Total Factor Productivity. The TFP does not consider the depletion of environmental resources caused by economic growth, which would distort the evaluation of changes in economic performance and mislead policy recommendations. Chung et al. [29] proposed a directional distance function which can regard pollution emissions as undesired output to measure GTFP considering environmental factors. Since then, this method has been widely used. Kumar [30] used the Malmquist-Luenberger (ML) index to measure the GTFP of 41 countries. By comparing with the traditional TFP, it was found that GTFP was not significantly different from the traditional TFP. The difference between the Malmquist-Luenberger (ML) index is quite significant. Oh and Heshmati [31] also used the ML index when studying the GTFP of 26 OECD countries. The research results show that there was a significant difference between traditional TFP and GTFP in terms of index decomposition. Based on previous studies, this paper defines GTFP as follows: in the traditional TFP analysis framework, energy consumption is used as an input indicator, and pollutant emissions are taken as undesired output and included in the input-output efficiency analysis. The TFP obtained is the GTFP, which not only considers traditional labor, capital, and other factor inputs and output indicators such as added value but also considers energy consumption (oil, natural gas, electricity consumption, etc.) and pollution emissions (industrial wastewater, waste gas, solids) and other elements, so that the results obtained more reflect the actual economic activities.

The GTFP has gradually become the main driving force for the transformation of economic development mode [32]. Referring to the production possibility set including expected output and unexpected output constructed by Fare 


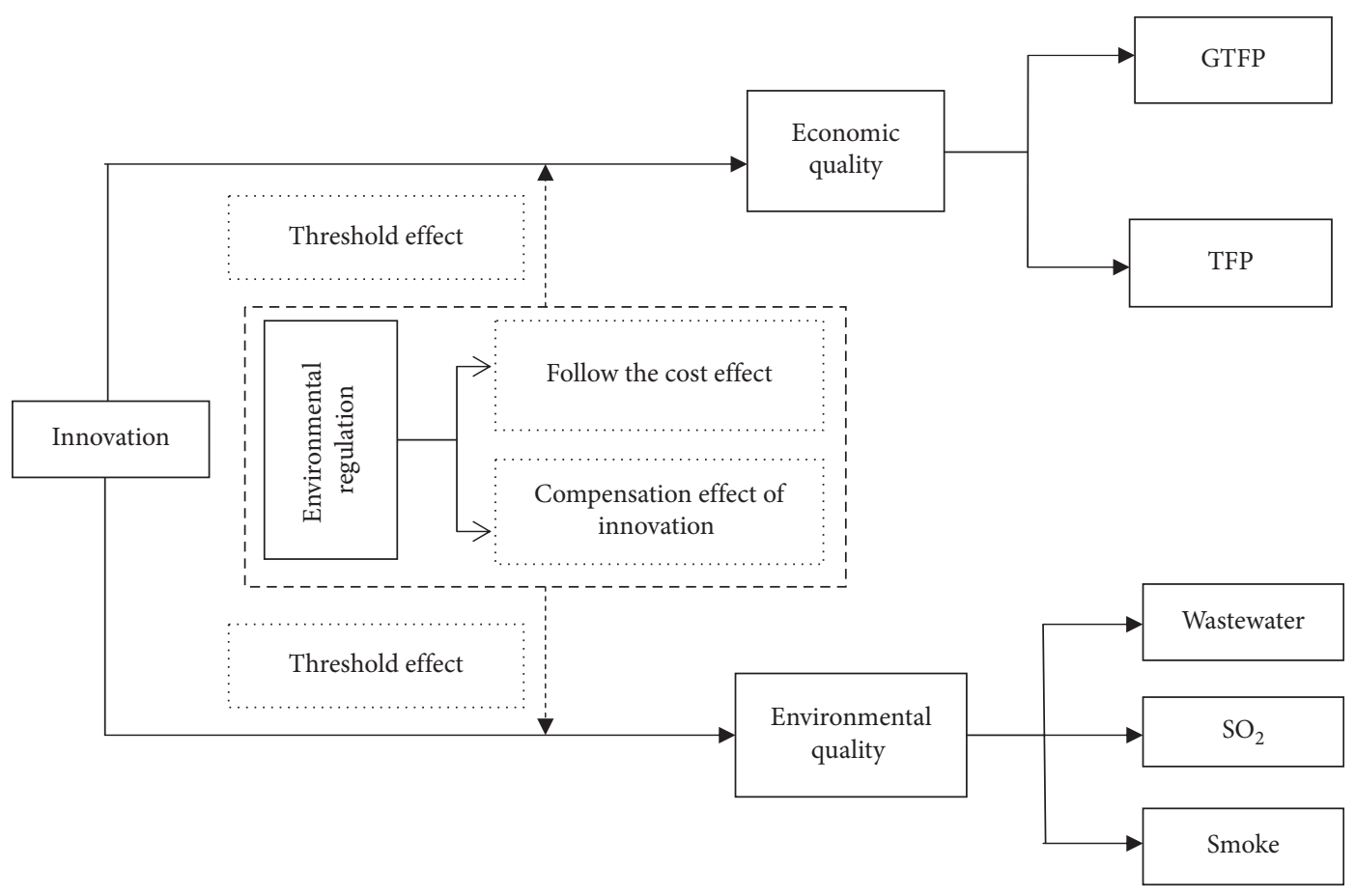

FIgURE 1: Theoretical framework.

et al., this paper uses Malmquist-Luenberger (ML) index of nonradial SBM directional distance to measure the dynamic change of GTFP. The ML index used in this paper is shown as follows.

$$
\begin{aligned}
\mathrm{ML}_{t}^{t+1} & =\left\{\frac{\left[1+\overrightarrow{D_{0}^{t}}\left(x^{t}, y^{t}, b^{t}\right)\right]}{\left[1+\overrightarrow{D_{0}^{t}}\left(x^{t+1}, y^{t+1}, b^{t+1}\right)\right]} \times \frac{\left[1+\overrightarrow{D_{0}^{t+1}}\left(x^{t}, y^{t}, b^{t}\right)\right]}{\left[1+\overrightarrow{D_{0}^{t+1}}\left(x^{t+1}, y^{t+1}, b^{t+1}\right)\right]}\right\}^{1 / 2} \\
& =\frac{1+\overrightarrow{D_{0}}\left(x^{t}, y^{t}, b^{t}\right)}{1+\overrightarrow{D_{0}}\left(x^{t+1}, y^{t+1}, b^{t+1}\right)} \times\left\{\frac{\left[1+\overrightarrow{D_{0}^{t}}\left(x^{t}, y^{t}, b^{t}\right)\right]}{\left[1+\overrightarrow{D_{0}^{t}}\left(x^{t}, y^{t}, b^{t}\right)\right]} \times \frac{\left[1+\overrightarrow{D_{0}^{t+1}}\left(x^{t+1}, y^{t+1}, b^{t+1}\right)\right]}{\left[1+\overrightarrow{D_{0}^{t}}\left(x^{t+1}, y^{t+1}, b^{t+1}\right)\right]}\right\} \\
& =\operatorname{GTEC}_{t}^{t+1} \times \mathrm{GTC}_{t}^{t+1} .
\end{aligned}
$$

In the formula, $x^{t}, y^{t}$, and $b^{t}$, respectively, represent input indicators, expected output, and undesired output. GTC is the technological progress index and GTEC is the technological efficiency change index. Similar to the calculation of TFP, ML is the growth rate of GTFP. We need to convert the ML index to GTFP. That is, we set 2005 as the base period. Specifically, the GTFP in 2005 is 1 , and the GTFP from 2006 to 2016 is obtained in turn.

The selection of specific input-output indicators is shown in Table 1. This paper selects 193 cities to calculate GTFP and TFP. The research data comes from the 2006-2016 "City Statistical Yearbook." The input indicators of TFP include only human input and capital input, and output only includes expected output; while the input indicators of GTFP include human input, capital input, and energy consumption; the output indicators include expected output and undesired output.

3.2. Construction of the Measurement Model. In order to explore the nonlinear relationship between environmental regulations and GTFP due to differences in urban economic development levels, this paper uses the panel threshold regression method developed by Hansen [37] to estimate the parameters. In order to analyze the nonlinear effects of innovation quality on GTFP, TFP, and pollutant emissions under different environmental regulation intensities, we take environmental regulation (REGU) as a threshold variable and construct its relationship with GTFP and TFP. The threshold panel model between and pollutant discharge $(\mathrm{CON})$ and the specific form is as follows: 


$$
\begin{aligned}
\operatorname{GTFP}_{i, t} & =c+\beta_{1} \mathrm{RD}_{i, t} I\left(\mathrm{REGU}_{i, t} \leq \gamma_{1}\right)+\beta_{2} \mathrm{RD}_{i, t} I\left(\gamma_{1}<\mathrm{REGU}_{i, t}<\gamma_{2}\right)+\cdots+\beta_{n} \mathrm{RD}_{i, t} I\left(\mathrm{REGU}_{i, t}>\gamma_{n}\right)+\theta X_{i, t}+u_{i}+e_{i, t}, \\
\operatorname{TFP}_{i, t} & =c+\beta_{1} \mathrm{RD}_{i, t} I\left(\mathrm{REGU}_{i, t} \leq \gamma_{1}\right)+\beta_{2} \mathrm{RD}_{i, t} I\left(\gamma_{1}<\mathrm{REGU}_{i, t}<\gamma_{2}\right)+\cdots+\beta_{n} \mathrm{RD}_{i, t} I\left(\mathrm{REGU}_{i, t}>\gamma_{n}\right)+\theta X_{i, t}+u_{i}+e_{i, t}, \\
\mathrm{CON}_{i, t} & =c+\beta_{1} \mathrm{RD}_{i, t} I\left(\mathrm{REGU}_{i, t} \leq \gamma_{1}\right)+\beta_{2} \mathrm{RD}_{i, t} \mathrm{I}\left(\gamma_{1}<\mathrm{REGU}_{i, t}<\gamma_{2}\right)+\cdots+\beta_{n} \mathrm{RD}_{i, t} \mathrm{I}\left(\mathrm{REGU}_{i, t}>\gamma_{n}\right)+\theta X_{i, t}+u_{i}+e_{i, t},
\end{aligned}
$$

where $\mathrm{GTFP}_{i, t}, \mathrm{TFP}_{i, t}$, and $\mathrm{CON}_{i, t}$ are explained variables. Among them, $\mathrm{CON}_{i, t}$ represents the pollutant emission, and four indicators are selected here (industrial wastewater emissions, industrial sulfur dioxide emissions, industrial smoke, and dust emissions). $\mathrm{RD}_{i, t}$ is the quality of urban innovation; this article chooses the number of patents to express; REGU ${ }_{i, t}$ expresses the intensity of environmental regulation, which is a threshold variable; $X_{i, t}$ is a set of control variables, including industrial structure (IS), government behavior (GOV), local openness (FDI), and infrastructure (ROD). $e_{i, t}$ is a random disturbance item; $u_{i}$ is an individual effect. $I($.$) is an indicative function. \gamma$ is the threshold value.

3.3. Variable Selection. Explained variables are as follows. (1) Urban green total factor productivity: GTFP is measured by nonradial SBM directional distance function and ML index method [38, 39]. (2) The total factor productivity: TFP adopts a data envelopment analysis method using two inputs (capital and labor inputs) and one output (expected output) [28]. (3) Four indicators are used to measure pollutant emissions: industrial wastewater discharge (IWD) emissions $[40,41]$, industrial sulfur dioxide discharge $\left(\mathrm{SO}_{2}\right)$ emissions [42], industrial smoke and dust discharge (ISD) emissions $[43,44]$.

The core explanatory variable of this article is the number of patents (INV, ten thousand yuan/piece). The number of patents $=$ the number of invention patents + the number of utility patents + the number of appearance patents. With reference to the usual practice of such research and considering the availability of data, this article uses the number of patents granted to measure regional innovation capabilities. Generally speaking, the process of innovation activities can be divided into three main links: innovation input, innovation organization, and innovation output. Patent data, as the output of innovation, reflects the final effect of innovation activities and has the characteristics of comparability and easy access.

The threshold variable of this article is the intensity of environmental regulation (REGU). This article quantifies the intensity of urban environmental regulation by obtaining the entropy value of the pollutant emission reduction effect after standardization.

In addition, referring to existing research, this paper selects industrial structure (IS), government behavior (GOV), local openness (FDI), and infrastructure (ROD) as control variables. Specific variable definitions are shown in Table 2.

Based on the previous research methods, this paper selects relevant data from 193 cities in China from 2006 to 2016 and eliminates cities with more data missing. The relevant data used in this section comes from the China
Statistical Yearbook, China Labor Statistical Yearbook, China Energy Statistical Yearbook, China Environment Statistical Yearbook, China City Statistical Yearbook, and statistical yearbooks of various provinces and cities.

\section{Empirical Analysis}

4.1. Threshold Model. The results of the threshold effect test using environmental regulations as the threshold variable are shown in Table 3. In order to better test the impact of innovation quality on GTFP under different environmental regulatory intensities, this paper uses bootstrap sampling 300 times to obtain the corresponding $P$ value and confidence interval [37]. It can be seen from Table 3 that in the model with GTFP and TFP as the explained variables, the threshold test results rejected the single threshold and three thresholds, while the double threshold passed the threshold effect test, indicating that the two models should choose dual thresholds. When explaining the impact of innovation quality on GTFP under different environmental regulatory intensities; the two thresholds divide the environmental regulatory intensity into three intervals, which are low level $($ REGU $\leq 0.8591)$ and medium level $(0.8591<\mathrm{REGU} \leq 0.8633)$ and high level $(\mathrm{REGU}>0.8633)$. When the explained variable is TFP, the three intervals are low level (REGU $\leq 0.5955)$, medium level $(0.5955<\mathrm{REGU} \leq 0.6073)$, and high level $(\mathrm{REGU}>0.6073)$. Among the models in which pollutant emissions are interpreted as variables, only $\mathrm{SO}_{2}$ emissions have a threshold effect, and it is a dual-threshold model. The threshold values are 0.5444 and 0.7136 , respectively. The three environmental regulatory intensity intervals are low level $(\mathrm{REGU} \leq 0.5444)$, medium level $(0.5444<\mathrm{REGU} \leq 0.7136)$, and high level (REGU $>0.7136$ ), and none of the others have thresholds effect.

4.2. Regression Results. If the threshold effect of the intensity of environmental regulation is not taken into account, the effect of innovation quality on GTFP, TFP, and pollutant emissions is shown in Table 4; that is, the panel regression results are as follows. First of all, the models in this article have passed the Hausmann test. The test results show that when the explained variables are GTFP, TFP, $\mathrm{SO}_{2}$, and IWD, the null hypothesis is rejected. That is, the fixed-effects model is selected and explained. When the variable is ISD, the null hypothesis is accepted and the random-effects model is selected.

It can be seen from the test results that the level of innovation has a positive impact on GTFP and TFP at the $1 \%$ and $10 \%$ significance levels, respectively, and the impact coefficients are 0.054 and 0.012 , respectively. The GTFP and TFP will increase by 0.054 and 0.012 units, respectively, 
TABLE 1: Meaning and measurement of GTFP and TFP.

\begin{tabular}{|c|c|c|c|}
\hline First-level index & Secondary indicators & Three-level indicators & References \\
\hline \multirow[t]{2}{*}{ Investment index } & Capital investment & $\begin{array}{l}\text { Number of employees in each city } \\
\text { Perpetual inventory method is used to calculate capital stock to measure } \\
\text { capital investment; the formula is } K_{i, t}=K_{i, t-1}\left(1-\delta_{i, t}\right)+I_{i, t} \text {, where } K_{i, t} \\
\text { and } K_{i, t-1} \text { represent the depreciation rate of the city } i \text { in year } t \text { and } I_{i, t} \text { is } \\
\text { the total fixed-asset investment of city } i \text { in } t\end{array}$ & [33-35] \\
\hline & $\begin{array}{c}\text { Energy consumption (special } \\
\text { for GTFP) }\end{array}$ & City annual electricity consumption & \\
\hline $\begin{array}{l}\text { Expected output } \\
\text { indicator }\end{array}$ & Economic output & GDP calculated at constant prices in 2000 & {$[20]$} \\
\hline $\begin{array}{l}\text { Unexpected output } \\
\text { indicators }\end{array}$ & $\begin{array}{l}\text { Environmental pollution } \\
\text { index (special for GTFP) }\end{array}$ & $\begin{array}{l}\text { Industrial wastewater emissions, industrial sulfur dioxide emissions, } \\
\text { and industrial smoke and dust emissions; we use the entropy method to } \\
\text { determine the weight of undesired output to calculate the } \\
\text { comprehensive index of undesired output }\end{array}$ & {$[36]$} \\
\hline
\end{tabular}

TABLe 2: Variable definition.

\begin{tabular}{|c|c|c|c|c|}
\hline $\begin{array}{l}\text { Variable } \\
\text { classification }\end{array}$ & Variable name & Variable interpretation & Symbol & References \\
\hline \multirow{3}{*}{$\begin{array}{l}\text { Explained } \\
\text { variable }\end{array}$} & $\begin{array}{l}\text { Green total factor } \\
\text { productivity }\end{array}$ & $\begin{array}{l}\text { Malmquist-Luenberger index based on nonradial SBM directional } \\
\text { distance }\end{array}$ & GTFP & {$[38,39]$} \\
\hline & $\begin{array}{l}\text { Total factor } \\
\text { productivity }\end{array}$ & DEA-Malmquist index & TFP & [28] \\
\hline & Emissions & $\begin{array}{l}\text { Industrial wastewater discharge (IWD), industrial sulfur dioxide } \\
\text { discharge }\left(\mathrm{SO}_{2}\right) \text {, industrial smoke and dust discharge (ISD) }\end{array}$ & $\mathrm{CON}$ & [40-44] \\
\hline $\begin{array}{l}\text { Explanatory } \\
\text { variables }\end{array}$ & $\begin{array}{l}\text { Number of patents (ten } \\
\text { thousand) }\end{array}$ & $\begin{array}{c}\text { Number of patents }=\text { number of invention patents }+ \text { number of utility } \\
\text { patents }+ \text { number of appearance patents }\end{array}$ & INV & {$[45,46]$} \\
\hline $\begin{array}{l}\text { Threshold } \\
\text { variable }\end{array}$ & $\begin{array}{l}\text { Environmental } \\
\text { regulation }\end{array}$ & $\begin{array}{c}\text { Entropy weight method based on five indicators: industrial } \mathrm{SO}_{2} \text { removal } \\
\text { rate, smoke removal rate, the comprehensive utilization rate of } \\
\text { industrial solid waste, domestic sewage treatment rate, and domestic } \\
\text { garbage innocuous treatment rate }\end{array}$ & REGU & {$[47,48]$} \\
\hline \multirow{4}{*}{ Control variable } & Industrial structure & $\begin{array}{c}\text { The ratio of the added value of the tertiary industry to the added value of } \\
\text { the secondary industry }\end{array}$ & IS & {$[49,50]$} \\
\hline & $\begin{array}{l}\text { Open to the outside } \\
\text { world }\end{array}$ & $\begin{array}{c}\text { The proportion of the output value of foreign-invested enterprises in the } \\
\text { regional GDP }\end{array}$ & FDI & {$[51,52]$} \\
\hline & Government action & $\begin{array}{c}\text { Government expenditure on teaching and research as a percentage of } \\
\text { the regional GDP }\end{array}$ & GOV & {$[53]$} \\
\hline & Infrastructure & Urban road area per capita & ROD & [54] \\
\hline
\end{tabular}

when the innovation level increases by 1 unit. Therefore, the coefficient and significance of the impact of innovation on GTFP are greater than those of TFP. As the level of innovation increases, both GTFP and TFP will increase. On the other hand, the level of innovation has a significant negative impact on $\mathrm{SO}_{2}$ and IWD, and the coefficient and significance of the impact on $\mathrm{SO}_{2}$ are relatively large. That is to say, when the innovation level increases by one unit, the $\mathrm{SO}_{2}$ emission and wastewater emission will decrease by 1.2 units and 1.47 units, respectively. Innovation plays a more significant role in $\mathrm{SO}_{2}$ emission reduction.

In the random-effects model, the increase in innovation level has no significant impact on ISD. It can be seen from the results that, regardless of the intensity of environmental regulations, innovation has a significant effect on GTFP, the improvement of TFP, and the reduction of pollutant emissions, which is conducive to improving environmental and economic quality.
In order to verify the threshold effect of environmental regulation, this article first examines the relationship between innovation quality and GTFP at different stages of environmental regulation intensity. The results are shown in the first column of Table 5 . The intensity of environmental regulations is divided into three intervals by the threshold value: low level (REGU $\leq 0.8591)$, medium level $(0.8591<$ REGU $\leq 0.8633)$, and high level (REGU >0.8633). When the intensity of environmental regulation is a low level $(\mathrm{REGU} \leq 0.8591)$ and a medium intensity level of $0.8591<\mathrm{REGU} \leq 0.8633$ ), the quality of innovation has a positive impact on GTFP, but it is not significant. When the intensity of environmental regulation is at a high level (REGU > 0.8633), the quality of innovation has a significant positive impact on the GTFP at the level of 5\%, with an impact coefficient of 0.06 , indicating that under a higher level of environmental regulation, the innovation has a significant positive effect on GTFP. For every unit of innovation, GTFP will increase by 0.06 units. 
TABLE 3: The threshold effect test of environmental regulation.

\begin{tabular}{|c|c|c|c|c|c|}
\hline Explained variable & Model & Threshold & $F$ value & $P$ value & BS times \\
\hline \multirow{4}{*}{ GTFP } & Single threshold & 0.8498 & 12.83 & 0.357 & 300 \\
\hline & Double threshold & 0.8591 & $20.15^{*}$ & 0.09 & 300 \\
\hline & & 0.8631 & & & \\
\hline & Three thresholds & 0.8967 & 4.2 & 0.6 & 300 \\
\hline \multirow{4}{*}{ TFP } & Single threshold & 0.6173 & 19.01 & 0.12 & 300 \\
\hline & Double threshold & 0.5955 & $84.6^{* *}$ & 0.33 & 300 \\
\hline & & 0.6073 & & & \\
\hline & Three thresholds & 0.7241 & 13.57 & 0.42 & 300 \\
\hline \multirow{4}{*}{ Industrial sulfur dioxide emissions } & Single threshold & 0.5444 & $84.89^{* * *}$ & 0 & 300 \\
\hline & Double threshold & 0.5444 & $25.62^{* * *}$ & 0 & 300 \\
\hline & & 0.7136 & & & \\
\hline & Three thresholds & 0.4864 & 22.02 & 0.433 & 300 \\
\hline \multirow{4}{*}{ Industrial smoke and dust emissions } & Single threshold & 0.5007 & 1.19 & 0.7367 & 300 \\
\hline & Double threshold & 0.5293 & 1.22 & 0.7311 & 300 \\
\hline & & 0.5373 & & & \\
\hline & Three thresholds & 0.4011 & 0.57 & 0.81 & 300 \\
\hline \multirow{4}{*}{ Industrial wastewater discharge } & Single threshold & 0.9116 & 6.78 & 0.433 & 300 \\
\hline & Double threshold & 0.8692 & 9.13 & 0.21 & 300 \\
\hline & & 0.8591 & & & \\
\hline & Three thresholds & 0.8498 & 6.81 & 0.353 & 300 \\
\hline
\end{tabular}

Note: ${ }^{*},{ }^{* *}$, and ${ }^{* * *}$ represent that the estimated coefficients are significant at the $10 \%, 5 \%$, and $1 \%$ confidence levels, respectively.

TABLE 4: Panel regression results of innovation capability on GTFP, TFP, and pollutant emissions.

\begin{tabular}{|c|c|c|c|c|c|}
\hline & \multicolumn{4}{|c|}{ Fixed-effect model } & \multirow{2}{*}{$\begin{array}{c}\text { Random-effect model } \\
\text { ISD }\end{array}$} \\
\hline & GTFP & TFP & $\mathrm{SO}_{2}$ & IWD & \\
\hline $\mathrm{RD}$ & $\begin{array}{c}0.054^{* * *} \\
(0.012)\end{array}$ & $\begin{array}{l}0.012^{*} \\
(0.007)\end{array}$ & $\begin{array}{c}-1.200^{* * *} \\
(0.164)\end{array}$ & $\begin{array}{c}-1.47^{* * *} \\
(0.244)\end{array}$ & $\begin{array}{c}0.061 \\
(0.382)\end{array}$ \\
\hline IS & $\begin{array}{c}0.101^{* * *} \\
(0.022)\end{array}$ & $\begin{array}{c}0.046^{* * * *} \\
(0.012)\end{array}$ & $\begin{array}{c}-1.625^{* * *} \\
(0.286)\end{array}$ & $\begin{array}{l}-0.31 \\
(0.426)\end{array}$ & $\begin{array}{l}-0.344 \\
(0.564)\end{array}$ \\
\hline FDI & $\begin{array}{l}-0.042 \\
(0.064)\end{array}$ & $\begin{array}{l}-0.041 \\
(0.035)\end{array}$ & $\begin{array}{l}2.024^{* *} \\
(0.839)\end{array}$ & $\begin{array}{l}-0.54 \\
(1.25)\end{array}$ & $\begin{array}{l}-1.11 \\
(1.12)\end{array}$ \\
\hline ROD & $\begin{array}{c}0.001 \\
(0.001)\end{array}$ & $\begin{array}{c}0.002^{* * * *} \\
(0.001)\end{array}$ & $\begin{array}{c}-0.064^{* * *} \\
(0.016)\end{array}$ & $\begin{array}{c}-0.07^{* * * *} \\
(0.024)\end{array}$ & $\begin{array}{c}0.0192 \\
(0.036)\end{array}$ \\
\hline GOV & $\begin{array}{c}0.011^{* * *} \\
(0.002)\end{array}$ & $\begin{array}{c}-0.0003 \\
(0.001)\end{array}$ & $\begin{array}{c}-0.137^{* * * *} \\
(0.026)\end{array}$ & $\begin{array}{c}-0.141^{* * * *} \\
(0.039)\end{array}$ & $\begin{array}{l}0.0497 \\
(0.039)\end{array}$ \\
\hline Constant & $\begin{array}{c}0.821^{* * * *} \\
(0.028)\end{array}$ & $\begin{array}{c}0.854^{* * *} \\
(0.016)\end{array}$ & $\begin{array}{c}9.343^{* * *} \\
(0.373)\end{array}$ & $\begin{array}{c}10.935^{* * *} \\
(0.555)\end{array}$ & $\begin{array}{l}3.41^{* * * *} \\
(0.713)\end{array}$ \\
\hline Observations & 2123 & 2123 & 2123 & 2123 & 2123 \\
\hline Numbers & 193 & 193 & 193 & 193 & 193 \\
\hline$R$-squared & 0.09 & 0.012 & 0.1757 & 0.1985 & 0.01 \\
\hline
\end{tabular}

Note: ${ }^{*},{ }^{* *}$, and ${ }^{* * *}$ represent that the estimated coefficients are significant at the $10 \%, 5 \%$, and $1 \%$ confidence levels, respectively.

The results of the impact of innovation quality on TFP at different stages of environmental regulation intensity are shown in the second column of Table 5. The threshold value of environmental regulation intensity is divided into three intervals: low level (REGU $\leq 0.5955)$, medium level (0.5955) $<$ REGU $\leq 0.6073$ ), and high level (REGU > 0.6073). When the intensity of environmental regulation is at a low level (REG$\mathrm{U} \leq 0.5955)$, the quality of innovation has a positive impact on TFP, but the impact coefficient is only 0.002 and is not significant; when the intensity of environmental regulation reaches the second interval level $(0.5955<$ REGU $\leq 0.6073)$, the influence coefficient of innovation quality on TFP reaches 0.768 and is significantly positively correlated at the $1 \%$ level, indicating that under the medium intensity of environmental regulations, the TFP increases by 0.768 units for every unit of urban innovation level. When the intensity of environmental regulation reaches a high level (REGU > 0.6073), although the impact of innovation quality on TFP is still positive, it is not significant, and the impact coefficient is only 0.012 . The results show that as the intensity of environmental regulation increases, the positive impact of innovation on TFP first rises and then declines.

The results of the impact of innovation quality on $\mathrm{SO}_{2}$ emissions at different stages of environmental regulation intensity are shown in the third column of Table 5. The threshold value of environmental regulation intensity is divided into three intervals: low level (REGU $\leq 0.5444)$, medium level $(0.5444<\mathrm{REGU} \leq 0.7136)$, and high level (REGU > 0.7136). At a low level of environmental regulation intensity 
TABle 5: The impact of innovation on productivity and pollutants under environmental regulation.

\begin{tabular}{lccc}
\hline & \multicolumn{3}{c}{ Threshold effect model } \\
& GTFP & TFP & $\mathrm{SO}_{2}$ \\
\hline REGU-1 & 0.047 & 0.0002 & $4.64^{* * *}$ \\
& $(0.031)$ & $(0.049)$ & $(1.59)$ \\
REGU-2 & 0.194 & $0.768^{* * *}$ & $-0.448^{*}$ \\
& $(0.122)$ & $(0.106)$ & $(0.237)$ \\
REGU-3 & $0.06^{* *}$ & 0.012 & $-1.45^{* * *}$ \\
& $(0.004)$ & $(0.011)$ & $(0.385)$ \\
IS & $0.097^{*}$ & $0.047^{* *}$ & $-1.504^{* * *}$ \\
& $(0.053)$ & $(0.021)$ & $(0.424)$ \\
FDI & -0.018 & -0.05 & 1.045 \\
& $(0.119)$ & $(0.039)$ & $(1.20)$ \\
ROD & 0.0004 & $0.002^{* *}$ & $-0.061^{* *}$ \\
& $(0.0017)$ & $(0.01)$ & $(0.025)$ \\
GOV & $0.011^{* * *}$ & -0.001 & $-0.118^{* *}$ \\
& $(0.004)$ & $(0.002)$ & $(0.052)$ \\
Constant & $0.822^{* * *}$ & $0.854^{* * *}$ & $9.07^{* * *}$ \\
Observations & $(0.0611)$ & $(0.024)$ & $(0.615)$ \\
Numbers & 2123 & 2123 & 2123 \\
$R$-squared & 193 & 193 & 193 \\
\hline
\end{tabular}

Note: ${ }^{*},{ }^{* *}$, and ${ }^{* * *}$ represent that the estimated coefficients are significant at the $10 \%, 5 \%$, and $1 \%$ confidence levels, respectively. The standard errors of the coefficients are marked in parentheses.

(REGU $\leq 0.5444)$, the quality of innovation has a significant positive impact on $\mathrm{SO}_{2}$ emissions at the $1 \%$ level, indicating that under this environmental regulation interval, the improvement of innovation quality not only does not reduce the emission of $\mathrm{SO}_{2}$ but also increases the emission of $\mathrm{SO}_{2}$; when the intensity of environmental regulations reaches the second interval level $(0.5444<\mathrm{REGU} \leq 0.7136)$, the innovation quality's effect on $\mathrm{SO}_{2}$ emissions is significantly negative at the $10 \%$ level, with a coefficient of 0.448 . It shows that the intensity of environmental regulation is at the middle-income level, and as the city's innovation level increases, $\mathrm{SO}_{2}$ emissions begin to decline. When the intensity of environmental regulation reaches a high level (REGU > 0.7136), the impact of innovation quality on TFP is significantly negative at the $1 \%$ level, with a coefficient of 1.45 . The impact coefficient and significance in the high range of environmental regulations are better than those in the medium range, indicating that with the improvement of environmental regulations, the impact of innovation on $\mathrm{SO}_{2}$ emission reduction is gradually increasing.

In addition, among the control variables, the proportion of tertiary industry has a significant positive impact on the improvement of GTFP and TFP, and a significant negative impact on $\mathrm{SO}_{2}$ emissions. In other words, the increase in the tertiary industry can help cities take the path of sustainable development. Infrastructure (ROD) has a significant role in promoting the improvement of TFP and also has a significant negative effect on $\mathrm{SO}_{2}$ emissions, indicating that strengthening infrastructure construction can help cities to save energy and reduce emissions while promoting the increase in TFP. The government's policy preference for technology and education (GOV) has a significant positive impact on the improvement of GTFP and a significant negative impact on $\mathrm{SO}_{2}$ emissions. It shows that the government's policy preference can enable cities to promote the improvement of economic quality while ensuring environmental quality.

It can be seen from this that the positive effect of innovation on GTFP requires a higher intensity of environmental regulation to cooperate. When the intensity of environmental regulation is at a high level (REGU > 0.8633), the quality of innovation has a significant positive impact on the $5 \%$ level of GTFP, with an impact coefficient of 0.06 . A lower level of environmental regulation can stimulate the positive effect of innovation on TFP. With a moderate level of environmental regulation $(0.5955<\mathrm{REGU} \leq 0.6073)$, the increase in the level of urban innovation will result in a significant increase in TFP. During this period, innovation also has a significant positive impact on the $\mathrm{SO}_{2}$ emission reduction effect.

4.3. Hysteresis Test. In order to test the stability of the model, this paper conducts a lag test on the model. The test results of the threshold effect under the first period of lagging innovation quality are shown in Table 6 . This paper uses bootstrap sampling 300 times to obtain the corresponding $P$ value and confidence interval [37]. It can be seen from Table 6 that in the model with GTFP as the explained variable, environmental regulation no longer has a double threshold effect. In the model with TFP as the explained variable, the threshold test results still rejected the single threshold and three thresholds, while the double threshold passed the threshold effect test, indicating that the double threshold should be chosen. The three levels of environmental regulation intensity are divided into a low level $(\mathrm{REGU} \leq 0.5985)$, medium level $(0.5985<\mathrm{REGU} \leq 0.6103)$, and high level (REGU $>0.6103$ ).

When the explained variable is pollutant emissions, the lagging effect of innovation quality on $\mathrm{SO}_{2}$ emissions still has a double threshold effect, and the threshold values are 0.6258 and 0.8206 , respectively. The three levels of environmental regulation intensity are divided into a low level (REG$\mathrm{U} \leq 0.6258)$, medium level $(0.6258<\mathrm{REGU} \leq 0.8206)$, and high level (REGU > 0.8206). In addition, the lagging effect of innovation quality on industrial wastewater discharge has a double threshold effect, with threshold values of 0.8048 and 0.8112 . The three levels of environmental regulation intensity are divided into a low level $(\mathrm{REGU} \leq 0.8048)$, medium level $(0.8048<\mathrm{REGU} \leq 0.8112)$, and high level (REGU > 0.8112).

This article first examines the lagging relationship between innovation quality and TFP at different stages of environmental regulation intensity. The results are shown in the first column of Table 7. When the explained variable is TFP, the three intervals of environmental regulation intensity are divided into a low level $(\mathrm{REGU} \leq 0.5985)$, medium level $(0.5985<\mathrm{REGU} \leq 0.6103)$, and high level (REGU $>0.6103)$. Although the impact of innovation on TFP is always positive, its significance will vary with the intensity of environmental regulations. When the intensity of environmental regulation is at a low level 
TABLE 6: Threshold effect test of the lag term.

\begin{tabular}{|c|c|c|c|c|c|}
\hline Explained variable & Model & Threshold valve & $F$ value & $P$ value & BS times \\
\hline \multirow{4}{*}{ GTFP } & Single threshold & 0.8512 & 15.44 & 0.3167 & 300 \\
\hline & Double threshold & 0.8595 & 12.22 & 0.22 & 300 \\
\hline & & 0.8631 & & & \\
\hline & Three thresholds & 0.8924 & 3.82 & 0.5633 & 300 \\
\hline \multirow{4}{*}{ TFP } & Single threshold & 0.6144 & $25.48^{* *}$ & 0.003 & 300 \\
\hline & Double threshold & 0.5985 & $76.32^{* * *}$ & 0.33 & 300 \\
\hline & & 0.6103 & & & \\
\hline & Three thresholds & 0.8595 & 10.63 & 0.92 & 300 \\
\hline \multirow{4}{*}{ Industrial sulfur dioxide emissions } & Single threshold & 0.6258 & $140.16^{* * *}$ & 0 & 300 \\
\hline & Double threshold & 0.6258 & $75.57^{* *}$ & 0.02 & 300 \\
\hline & & 0.8206 & & & \\
\hline & Three thresholds & 0.4864 & 42.09 & 0.7833 & 300 \\
\hline \multirow{4}{*}{ Industrial smoke and dust emissions } & Single threshold & 0.5009 & 1.2 & 0.7067 & 300 \\
\hline & Double threshold & 0.4014 & -0.27 & 1 & 300 \\
\hline & & 0.5432 & & & \\
\hline & Three thresholds & 0.8370 & 0.56 & 0.79 & 300 \\
\hline \multirow{4}{*}{ Industrial wastewater discharge } & Single threshold & 0.8112 & 5.31 & 0.4767 & 300 \\
\hline & Double threshold & 0.8048 & $16.56^{*}$ & 0.0067 & 300 \\
\hline & & 0.8112 & & & \\
\hline & Three thresholds & 0.831 & 16.21 & 0.3233 & 300 \\
\hline
\end{tabular}

Note: ${ }^{*},{ }^{* *}$, and ${ }^{* * *}$ represent that the estimated coefficients are significant at the $10 \%, 5 \%$, and $1 \%$ confidence levels, respectively.

TABLE 7: The results of the lagging regression of the threshold effect.

\begin{tabular}{lccc}
\hline & \multicolumn{3}{c}{ Threshold effect model } \\
& TFP & $\mathrm{SO}_{2}$ & IWD \\
\hline REGU-1 & 0.011 & $5.83^{* * *}$ & -1.75 \\
& $(0.037)$ & $(1.60)$ & $(1.12)$ \\
REGU-2 & $1.5^{* * *}$ & $-0.363^{*}$ & $-4.07^{* * *}$ \\
& $(0.9)$ & $(0.193)$ & $(1.023)$ \\
REGU-3 & 0.012 & $-1.55^{* * *}$ & $-1.499^{*}$ \\
& $(0.008)$ & $(0.38)$ & $(0.768)$ \\
IS & $0.059^{* * *}$ & $-1.79^{* * *}$ & -0.617 \\
& $(0.021)$ & $(0.434)$ & $(0.282)$ \\
FDI & $-0.079^{* *}$ & 1.14 & -0.451 \\
& $(0.039)$ & $(1.25)$ & $(0.826)$ \\
ROD & $0.003^{* *}$ & $-0.054^{* *}$ & -0.064 \\
& $(0.001)$ & $(0.025)$ & $(0.163)$ \\
GOV & $0.004^{* *}$ & $-0.109^{*}$ & -0.144 \\
& $(0.002)$ & $(0.057)$ & $(0.262)$ \\
Constant & $0.83^{* * *}$ & $9.077^{* * *}$ & $11.15^{* * * *}$ \\
Observations & $(0.025)$ & $(0.666)$ & $(1.17)$ \\
Numbers & 1930 & 1930 & 1930 \\
$R$-squared & 193 & 193 & 193 \\
\hline
\end{tabular}

Note: ${ }^{*},{ }^{* *}$, and ${ }^{* * *}$ represent that the estimated coefficients are significant at the $10 \%, 5 \%$, and $1 \%$ confidence levels, respectively. The standard errors of the coefficients are marked in parentheses.

$(\mathrm{REGU} \leq 0.5985)$ and a high level (REGU > 0.6103), the lagging effect of innovation quality on TFP is not significant. When the intensity of environmental regulation is at a medium level $(0.5985<$ REGU $\leq 0.6103)$, the quality of innovation has a significant lagging effect on TFP at the $1 \%$ level, with an impact coefficient of 1.5. For every unit of innovation increased, TFP increased by 1.5 units. This is basically consistent with the model test result without lag.
The lagging influence of innovation quality on $\mathrm{SO}_{2}$ emissions is shown in the second column of Table 7. For $\mathrm{SO}_{2}$, under the lower level (REGU $\leq 0.6258$ ) of environmental regulations, the quality of innovation has a positive lagging effect on $\mathrm{SO}_{2}$ emissions; that is, in the case of a period of lag, the improvement of the level of innovation not only does not help reduce $\mathrm{SO}_{2}$ emissions but has also increased $\mathrm{SO}_{2}$ emissions. When the intensity of environmental regulations is at a medium level $(0.6258<\mathrm{REGU} \leq 0.8206)$ and a high level (REG$\mathrm{U}>0.8206$ ), the innovation level has a negative impact on $\mathrm{SO}_{2}$ emissions, which are significant at the $10 \%$ and $1 \%$ levels, respectively. And the influence coefficient in the high-intensity interval is greater than that in the medium intensity interval. This changing trend is basically consistent with the result that there is no lagging term.

The lagging effect of innovation quality on industrial wastewater discharge (IWD) is shown in the third column of Table 7. The innovation level will always have a negative impact on IWD under the lag period, but the significance has changed. When the intensity of environmental regulation is at a low level (REG$\mathrm{U} \leq 0.8048$ ), the lagging effect of innovation is not significant; when the intensity of environmental regulation is at a medium level $(0.8048<\mathrm{REGU} \leq 0.8112)$ and a high level (REGU $>0.8112$ ), innovation has a significant negative impact on IWD at $1 \%$ and $10 \%$, and the impact coefficients are -4.07 and -1.499 , respectively. That is to say, for every unit of innovation increased, wastewater discharge will be reduced by 4.07 and 1.499 units, respectively. Although innovation will always reduce wastewater discharge, the effect of emission reduction is more effective under medium environmental regulation. 


\section{Discussion}

Regardless of the intensity of environmental regulations, innovation has a significant effect on GTFP, the improvement of TFP, and the reduction of pollutant emissions, which is conducive to improving environmental and economic quality. However, considering the threshold effect of environmental regulation, the regression model of innovation on these three types of explanatory variables has changed. Specifically, although innovation has always had a positive impact on GTFP and TFP under different environmental regulatory intensities, they are not always significant. When the impact of innovation on GTFP is positively significant, the range of environmental regulation intensity is high (REGU $>0.8633$ ), with a coefficient of 0.06 . That is to say, for every unit of innovation level increase, GTFP would significantly increase by 0.06 units. When the impact of innovation on TFP has positive significance, the difference of environmental regulation intensity is in the medium range $(0.5955<\mathrm{REGU} \leq 0.6073)$, and the coefficient is 0.768 . That is to say, for every unit of innovation level increase, TFP would significantly increase by 0.768 units. Regardless of the intensity of environmental regulations, the coefficients of influence of innovation on GTFP and TFP are 0.054 and 0.012 , respectively. That is to say, GTFP and TFP increase by 0.054 and 0.012 units, respectively, for each unit of innovation level. It can be seen from this that, considering the threshold effect of environmental regulations, the coefficients of influence of innovation on GTFP and TFP in their respective significant intervals are greater than before. In addition, the changes in the impact of innovation on $\mathrm{SO}_{2}$ emissions taking into account environmental regulations are also very significant. At different stages of the intensity of environmental regulations, the impact of innovation quality on $\mathrm{SO}_{2}$ emissions will go through a process from positive to negative. That is, as the intensity of environmental regulations increases, the positive effect of innovation quality on $\mathrm{SO}_{2}$ emission reduction becomes more and more obvious.

Since GTFP is a comprehensive indicator that integrates expected output (traditional TFP) and undesired output (environmental pollution), it is of great significance to analyze the mechanism of innovation under environmental regulations for GTFP. It can be seen from the results that environmental regulation will induce innovation to influence GTFP only at a higher intensity. Compared with traditional TFP, GTFP has higher requirements for the intensity of environmental regulation. The reason for this status is mainly from "following cost effect" and "innovation compensation effect."

On the one hand, environmental regulations will hinder the improvement of GTFP by inhibiting innovation and $\mathrm{R} \& \mathrm{D}$, that is, the effect of "following costs." This view believes that strict environmental regulations will increase the pollution control costs of enterprises in the region and inhibit their R\&D and innovation activities, thereby inhibiting GTFP [55-59]. On the other hand, environmental regulation will promote the increase of GTFP by increasing research and development, that is, the "innovation compensation" effect. For example, Naso et al. [60] believe that the increase in the intensity of environmental regulations in cities will "force" enterprises to increase R\&D and innovation in terms of factor input, energy consumption, energy conservation, and emission reduction, so as to improve their competitiveness to compensate. The negative impact is caused by the increase in environmental governance costs, which in turn promotes the improvement of urban GTFP $[61,62]$. When the intensity of environmental regulation is in the high range (REGU $>0.8633$ ), the effect of "innovation compensation" is greater than the effect of "compliance with cost." Therefore, in this range, environmental regulation stimulates the impact of innovation on GTFP.

\section{Conclusion}

Based on the Malmquist-Luenberger index and DEAMalmquist index, this paper, respectively, measures the green total factor productivity (GTFP) and total factor productivity (TFP) of 193 cities in China. On the basis of obtaining the GTFP, TFP, and various pollutant emissions of 193 cities, this paper selects environmental regulations as the threshold variable and the number of urban patents as the explanatory variable to measure the level of urban innovation. On this basis, we analyze the impact of innovation quality on economic quality and environmental pollution under different environmental regulatory intensities. The research results show that the impact of innovation on GTFP and TFP under different environmental regulations is always positive, but the impact coefficient and significance level vary. In addition, the impact of innovation on $\mathrm{SO}_{2}$ emissions under different environmental regulations has also changed. With the increase in the intensity of environmental regulations, it has undergone a process from positive to negative; that is, the effect of reducing emissions is gradually significant.

Specifically, although innovation has always had a positive impact on GTFP and TFP under different environmental regulatory intensities, they are not always significant. When the impact of innovation on GTFP is significant, the interval of environmental regulation intensity is REGU $>0.8633$, and when innovation is significant on TFP, the difference of environmental regulation intensity is $0.5955<\mathrm{REGU} \leq 0.6073$. There is no interaction between the intensity ranges of environmental regulations in these two types of situations.

In the model in which pollutant emissions are the explained variables, only $\mathrm{SO}_{2}$ emissions have a dualthreshold effect, and none of the others have a threshold effect. When innovation has a significant negative impact on $\mathrm{SO}_{2}$ emissions, the interval is at a medium level $(0.5444<$ REGU $\leq 0.7136)$ and a high level (REGU > 0.7136). And the significance and influence coefficient of the highlevel interval (REGU $>0.7136)$ are much better than those of the middle level $(0.5444<\mathrm{REGU} \leq 0.7136)$. It can be seen from this that the positive effect of innovation on GTFP requires a higher intensity of environmental regulation to cooperate. When the intensity of environmental regulation is at a high level (REGU > 0.8633), the quality of innovation has a significant positive impact on the $5 \%$ level of GTFP, 
with an impact coefficient of 0.06. A lower level of environmental regulation can stimulate the positive effect of innovation on TFP. With a moderate level of environmental regulation $(0.5955<\mathrm{REGU} \leq 0.6073)$, the increase in the level of urban innovation will result in a significant increase in TFP. In these two intervals, innovation also has a significant positive impact on the $\mathrm{SO}_{2}$ emission reduction effect. Specifically, when the environmental regulation interval where innovation quality has a significant positive impact on GTFP is at a high level (REGU >0.8633), within this interval, the coefficient of influence of innovation quality on $\mathrm{SO}_{2}$ emissions is -1.45 and is insignificant at the $1 \%$ level. When the quality of innovation has a significant positive impact on TFP, the environmental regulation interval is at a medium level $(0.5955<\mathrm{REGU} \leq 0.6073)$. In this interval, the coefficient of influence of innovation quality on $\mathrm{SO}_{2}$ emissions is -0.448 and is significant at the $10 \%$ level. It can be seen that, induced by environmental regulations, the impact of innovation on GTFP is closer to the impact on pollutant emission reduction. The reason for this is that the calculation process of GTFP takes into account the undesired output, that is, environmental pollution, and can better reflect the current two-way level of economic quality and environmental pollution.

Based on this, this article puts forward the following suggestions.

The implementation of strict environmental regulations is conducive to promoting China's construction of a resource and environment-friendly society and pushing China to embark on a path of sustainable low-carbon economic development. This means that China should increase investment in environmental protection, improve the treatment of industrial "three wastes," especially "exhaust gas" and "solid waste," implement a "green GDP" assessment mechanism, and earnestly implement energy saving and emission reduction strategies. To this end, the government should appropriately increase the intensity of environmental regulation and make good use of the two major environmental regulation tools, command-and-control, and market-incentive. For example, the implementation of a series of regulations and standards aimed at comprehensive protection and governance of resources and the environment, while encouraging and promoting enterprises to participate in the research and development of environmental-related technologies, such as preferential fiscal and tax policies, so as to mobilize enterprises' enthusiasm for technological innovation and form core competitiveness.

Innovation is the main source of promoting the increase of total factor productivity. However, China's current environmental protection efforts are not enough. It does not pay attention to the way that environmental regulations lead to technological innovation and promote total factor productivity. It does not fully realize that low-carbon technological innovation is the key to the practice of low-carbon economic development. To this end, China should build and improve a low-carbon technology innovation system, upgrade carbon reduction technology, carbon-free technology, and decarbonization technology, and ultimately achieve the goal of energy saving, emission reduction, and efficiency increase.
Based on panel data of 193 cities in China from 2006 to 2016, this paper analyzes the impact of innovation on GTFP and TFP under the circumstance of environmental regulation and draws some enlightening conclusions, which enriches theoretical and empirical research in relevant fields to some extent. However, due to the limitation of our research ability, some unresolved problems and imperfect parts need further research. Firstly, there is a lack of heterogeneity analysis. There is a gap in the economic level between cities; that is, there is regional heterogeneity. The urban economic foundation determines the innovation ability. This paper is not deep enough to study the regional heterogeneity, and in the future, we hope to make up for the shortage, enrich the theoretical expansion of innovation, and deepen the understanding of urban innovation. Secondly, due to the difficulties and shortcomings of data collection, this paper only selects urban data from 2006 to 2016. In the follow-up study, the calculation method of indicators needs to be further optimized, hoping to collect more data and further improve the accuracy of the conclusion.

\section{Data Availability}

The data used to support the findings of this study are available within the article and from the corresponding author upon request.

\section{Conflicts of Interest}

The authors declare that they have no conflicts of interest.

\section{References}

[1] A. Ll, A. Zz, A. Mz et al., "The effects of environmental regulation on outward foreign direct investment's reverse green technology spillover: crowding out or facilitation," Journal of Cleaner Production, vol. 284, Article ID 124689, 2020.

[2] K.-L. Wang, S.-Q. Pang, L.-L. Ding, and Z. Miao, "Combining the biennial Malmquist-Luenberger index and panel quantile regression to analyze the green total factor productivity of the industrial sector in China," Science of The Total Environment, vol. 739, Article ID 140280, 2020.

[3] B. Li and S. Wu, "Effects of local and civil environmental regulation on green total factor productivity in China: a spatial Durbin econometric analysis," Journal of Cleaner Production, vol. 153, pp. 342-353, 2016.

[4] W. Lin and B. Zza, "Impact and threshold effect of Internet technology upgrade on forestry green total factor productivity: evidence from China," Journal of Cleaner Production, vol. 271, Article ID 122657, 2020.

[5] B. Hwa, "Does China's outward direct investment improve green total factor productivity in the "Belt and Road" countries? Evidence from dynamic threshold panel model analysis," Journal of Environmental Management, vol. 275, Article ID 111295, 2020.

[6] M. Zhao, F. Liu, W. Sun, and X. Tao, "The relationship between environmental regulation and green total factor productivity in China: an empirical study based on the panel data of 177 cities," International Journal of Environmental Research and Public Health, vol. 17, no. 15, 2020. 
[7] B. Yuan and K. Zhang, "Can environmental regulation promote industrial innovation and productivity? Based on the strong and weak porter hypothesis," Chinese Journal of Population Resources \& Environment, vol. 15, pp. 54-68, 2017.

[8] V. Costantini and M. Mazzanti, "On the green and innovative side of trade competitiveness? The impact of environmental policies and innovation on EU exports," Research Policy, vol. 41, no. 1, pp. 132-153, 2012.

[9] J. Ederington, A. Levinson, and J. Minier, "Footloose and pollution-free," Review of Economics and Statistics, vol. 87, no. 1, pp. 92-99, 2005.

[10] S. B. Brunnermeier and M. A. Cohen, "Determinants of environmental innovation in US manufacturing industries," Journal of Environmental Economics and Management, vol. 45, no. 2, pp. 278-293, 2003.

[11] D. Vries, P. Frans, and C. Withagen, "Innovation and environmental stringency: the case of sulfur dioxide abatement," SSRN Electronic Journal, vol. 18, pp. 1-34, 2005.

[12] P. Linde, "Toward a new conception of the environmentcompetitiveness relationship," Journal of Economic Perspectives, vol. 9, pp. 97-118, 1995.

[13] E. Berman and L. T. M. Bui, "Environmental regulation and productivity: evidence from oil refineries," Review of Economics and Statistics, vol. 83, no. 3, pp. 498-510, 2001.

[14] S. Managi, J. J. Opaluch, D. Jin, and T. A. Grigalunas, "Environmental regulations and technological change in the offshore oil and gas industry," Land Economics, vol. 81, no. 2, pp. 303-319, 2005.

[15] N. Sawada, "Technology gap matters on spillover," Review of Development Economics, vol. 14, no. 1, pp. 103-120, 2010.

[16] C. Feder, "The effects of disruptive innovations on productivity," Technological Forecasting and Social Change, vol. 126, pp. 186-193, 2018.

[17] E. Huergo and J. Jaumandreu, "Firms' age, process innovation and productivity growth," International Journal of Industrial Organization, vol. 22, no. 4, pp. 541-559, 2004.

[18] E. Duguet, "Innovation height, spillovers and TFP growth at the firm level: evidence from French manufacturing," Economics of Innovation and New Technology, vol. 15, no. 4-5, pp. 415-442, 2006.

[19] R. Färe, S. Grosskopf, and C. Pasurkajr, "Environmental production functions and environmental directional distance functions," Energy, vol. 32, no. 7, pp. 1055-1066, 2007.

[20] H. Fukuyama and W. L. Weber, "A directional slacks-based measure of technical inefficiency," Socio-Economic Planning Sciences, vol. 43, no. 4, pp. 274-287, 2009.

[21] L. 1. Guo, Y. Qu, and M.-L. Tseng, "The interaction effects of environmental regulation and technological innovation on regional green growth performance," Journal of Cleaner Production, vol. 162, pp. 894-902, 2017.

[22] P. Chintrakarn, "Environmental regulation and U.S. states' technical inefficiency," Economics Letters, vol. 100, no. 3, pp. 363-365, 2008.

[23] Y. Rubashkina, M. Galeotti, and E. Verdolini, "Environmental regulation and competitiveness: empirical evidence on the porter hypothesis from European manufacturing sectors," Energy Policy, vol. 83, pp. 288-300, 2015.

[24] M. Wagner, "On the relationship between environmental management, environmental innovation and patenting: evidence from German manufacturing firms," Research Policy, vol. 36, no. 10, pp. 1587-1602, 2007.

[25] P. Teeter and J. Sandberg, "Constraining or enabling green capability development? How policy uncertainty affects organizational responses to flexible environmental regulations,"
British Journal of Management, vol. 28, no. 4, pp. 649-665, 2017.

[26] M. Hamamoto, "Environmental regulation and the productivity of Japanese manufacturing industries," Resource and Energy Economics, vol. 28, no. 4, pp. 299-312, 2006.

[27] C. H. Yang, Y. H. Tseng, and C. P. Chen, "Environmental regulations, induced $\mathrm{R} \& \mathrm{D}$, and productivity: evidence from Taiwan's manufacturing industries," Resource \& Energy Economics, vol. 34, no. 4, 2012.

[28] Shen, "Different interaction mechanisms of market structure in the construction industry TFP from the spatial perspective: a case study in China," KSCE Journal of Civil Engineering, vol. 20, no. 1, pp. 23-33, 2016.

[29] Y. H. Chung, R. Färe, and S. Grosskopf, "Productivity and undesirable outputs: a directional distance function approach," Journal of Environmental Management, vol. 51, no. 3, pp. 229-240, 1997.

[30] S. Kumar, "Environmentally sensitive productivity growth: a global analysis using Malmquist-Luenberger index," Ecological Economics, vol. 56, no. 2, pp. 280-293, 2006.

[31] D.-h. Oh and A. Heshmati, "A sequential Malmquist-Luenberger productivity index: environmentally sensitive productivity growth considering the progressive nature of technology," Energy Economics, vol. 32, no. 6, pp. 1345-1355, 2010.

[32] X. Li, C. Xu, B. Cheng et al., "Does environmental regulation improve the green total factor productivity of Chinese cities? A threshold effect analysis based on the economic development level," International Journal of Environmental Research and Public Health, vol. 18, no. 9, 2021.

[33] S. Kaneko and S. Managi, "Environmental productivity in China," Economics Bulletin, vol. 17, no. 2, pp. 1-10, 2004.

[34] S. Managi and S. Kaneko, "Economic growth and the environment in China: an empirical analysis of productivity," International Journal of Global Environmental Issues, vol. 6, no. 1, pp. 89-133, 2006.

[35] A. Hailu and T. S. Veeman, "Environmentally sensitive productivity analysis of the Canadian pulp and paper industry, 1959-1994: an input distance function approach," Journal of Environmental Economics and Management, vol. 40, no. 3, pp. 251-274, 2000.

[36] R. Färe and S. Grosskopf, "Directional distance functions and slacks-based measures of efficiency," European Journal of Operational Research, vol. 200, no. 1, pp. 320-322, 2010.

[37] M. T. Hansen, "The search-transfer problem: the role of weak ties in sharing knowledge across organization subunits," Administrative Science Quarterly, vol. 44, no. 1, pp. 82-111, 1999.

[38] Y. Li and Y. Chen, "Development of an SBM-ML model for the measurement of green total factor productivity: the case of pearl river delta urban agglomeration," Renewable and Sustainable Energy Reviews, vol. 145, Article ID 111131, 2021.

[39] Y. Li and S. Li, "The influence study on environmental regulation and green total factor productivity of China's manufacturing industry," Discrete Dynamics in Nature and Society, vol. 2021, Article ID 5580414, 15 pages, 2021.

[40] E. Konttinen, "From industrial consensus to environmental regulation: the coming of the Finnish industrial waste-water policy," Water Policy, vol. 1, no. 3, pp. 305-319, 1998.

[41] Q. S. Li, K. Kang, J. W. Zhu, Q. X. Meng, and S. J. Deng, "Study on the relationship between the economics and environment of Puyang city based on environmental kuznets curve," Advanced Materials Research, vol. 807-809, pp. 773-782, 2013. 
[42] M. Qin, L.-f. Fan, J. Li, and Y.-f. Li, "The income distribution effects of environmental regulation in China: the case of binding $\mathrm{SO}_{2}$ reduction targets," Journal of Asian Economics, vol. 73, Article ID 101272, 2021.

[43] R. Ma, C. Wang, Y. Jin et al., "Estimating the effects of economic agglomeration on haze pollution in Yangtze river delta China using an econometric analysis," Sustainability, vol. 11, no. 7, p. 1893, 2019.

[44] H. Xia, "Socioeconomic factors of industrial air pollutants in Zhejiang Province, China: decoupling and decomposition analysis," Environmental Science and Pollution Research, vol. 27, no. 22, pp. 28247-28266, 2020.

[45] E. Enkel, O. Gassmann, and H. Chesbrough, "Open R\&D and open innovation: exploring the phenomenon," $R$ \& $D$ Management, vol. 39, no. 4, pp. 311-316, 2010.

[46] M. A. Cole, R. J. R. Elliott, and K. Shimamoto, "Industrial characteristics, environmental regulations and air pollution: an analysis of the UK manufacturing sector," Journal of Environmental Economics and Management, vol. 50, no. 1, pp. 121-143, 2005.

[47] Y. Hao, Y. Deng, Z.-N. Lu, and H. Chen, "Is environmental regulation effective in China? Evidence from city-level panel data," Journal of Cleaner Production, vol. 188, pp. 966-976, 2018.

[48] Y. Song, T. Yang, Z. Li, X. Zhang, and M. Zhang, "Research on the direct and indirect effects of environmental regulation on environmental pollution: empirical evidence from 253 prefecture-level cities in China," Journal of Cleaner Production, vol. 269, Article ID 122425, 2020

[49] Z. Chen, X. Zhang, and F. Chen, "Have driving restrictions reduced air pollution: evidence from prefecture-level cities of China," Environmental Science and Pollution Research, vol. 28, no. 3, pp. 3106-3120, 2021.

[50] S. Zhao, "Privatization, FDI inflow and economic growth: evidence from China's provinces, 1978-2008," Applied Economics, vol. 45, no. 15, pp. 2127-2139, 2013.

[51] J. Ran, J. P. Voon, and G. Li, "How does FDI affect China? Evidence from industries and provinces," Journal of Comparative Economics, vol. 35, no. 4, pp. 774-799, 2007.

[52] R. Andersson, J. M. Quigley, and M. Wilhelmsson, "Urbanization, productivity, and innovation: evidence from investment in higher education," Journal of Urban Economics, vol. 66, no. 1, pp. 2-15, 2009.

[53] E. Resch, R. A. Bohne, T. Kvamsdal, and J. Lohne, "Impact of urban density and building height on energy use in cities," Energy Procedia, vol. 96, pp. 800-814, 2016.

[54] B. Yuan and K. Zhang, "Can environmental regulation promote industrial innovation and productivity? Based on the strong and weak porter hypothesis," Chinese Journal of Population Resources and Environment, vol. 15, no. 4, pp. 322-336, 2017.

[55] P. Lanoie, M. Patry, and R. Lajeunesse, "Environmental regulation and productivity: testing the porter hypothesis," Journal of Productivity Analysis, vol. 30, no. 2, pp. 121-128, 2008.

[56] T. Sueyoshi, M. Goto, and J. Shang, "Core business concentration vs. corporate diversification in the US electric utility industry: synergy and deregulation effects," Energy Policy, vol. 37, no. 11, pp. 4583-4594, 2009.

[57] R. Ramanathan, A. Black, P. Nath, and L. Muyldermans, "Impact of environmental regulations on innovation and performance in the UK industrial sector," Management Decision, vol. 48, no. 10, pp. 1493-1513, 2010.
[58] L. Hering and S. Poncet, "Environmental policy and exports: evidence from Chinese cities," Journal of Environmental Economics and Management, vol. 68, no. 2, pp. 296-318, 2014.

[59] M. Aklin, "Re-exploring the trade and environment nexus through the diffusion of pollution," Environmental and Resource Economics, vol. 64, no. 4, pp. 663-682, 2016.

[60] P. Naso, Y. Huang, and T. Swanson, "The impact of environmental regulation on Chinese spatial development," Economics of Transition and Institutional Change, vol. 28, no. 1, pp. 161-194, 2020.

[61] C. Zhang, H. Liu, H. T. A. Bressers, and K. S. Buchanan, "Productivity growth and environmental regulations-accounting for undesirable outputs: analysis of China's thirty provincial regions using the Malmquist-Luenberger index," Ecological Economics, vol. 70, no. 12, pp. 2369-2379, 2011.

[62] M. Song and S. Wang, "Can employment structure promote environment-biased technical progress?” Technological Forecasting and Social Change, vol. 112, pp. 285-292, 2016. 